\title{
Determinants of Bone Strength Estimated by Calcaneal Ultrasonography in Inuit Women from Nuuk (Greenland)
}

\author{
Alexandra-Cristina Paunescu, ${ }^{1}$ Pierre Ayotte, ${ }^{1,2}$ Sylvie Dodin, ${ }^{1}$ Éric Dewailly, \\ Gert Mulvad, ${ }^{3}$ Henning S. Pedersen, ${ }^{4}$ and Suzanne Côté ${ }^{1}$ \\ ${ }^{1}$ Axe Santé des Populations et Pratiques Optimales en Santé, Centre de Recherche du CHU de Québec, Québec, QC, Canada G1V $2 M 2$ \\ ${ }^{2}$ Laboratoire de Toxicologie, Institut National de Santé Publique du Québec, 945 Avenue Wolfe, Québec, QC, Canada G1V 5 B3 \\ ${ }^{3}$ Center of Primary Health Care, Queen Ingrid's Hospital and Greenland Center for Health Research, \\ University of Greenland, Nuuk 3900, Greenland \\ ${ }^{4}$ Medical Centre, Dronning Ingrids Hospital, Nuuk 3900, Greenland
}

Correspondence should be addressed to Pierre Ayotte; pierre.ayotte@inspq.qc.ca

Received 22 October 2013; Revised 19 January 2014; Accepted 19 February 2014; Published 27 March 2014

Academic Editor: Noriko Yoshimura

Copyright (C) 2014 Alexandra-Cristina Paunescu et al. This is an open access article distributed under the Creative Commons Attribution License, which permits unrestricted use, distribution, and reproduction in any medium, provided the original work is properly cited.

\begin{abstract}
This study was conducted to identify determinants of bone strength estimated by quantitative ultrasonography (QUS) at the calcaneus of Greenlandic Inuit women. A total of 153 Inuit women from Nuuk, aged from 49 to 64 years, participated in the first QUS measurement (year 2000) with an Achilles Lunar instrument (speed of sound (SOS); broadband ultrasound attenuation (BUA); stiffness index (SI)). A second measurement was performed two years later (year 2002) in 121 participants. Several factors known to be associated with bone strength were recorded at baseline for 118 of them. Determinants of QUS parameters were identified using an automatic (stepwise) selection of variables in linear regression. Significant determinants of baseline QUS measurements were age and body weight for all QUS parameters, height for BUA and SI, and hormone replacement therapy (HRT) use for SI. Significant predictors of follow-up QUS measurements were baseline QUS values, the smoking status and HRT use for all QUS parameters, omega-3/omega-6 PUFA content ratio of erythrocytes membrane phospholipids (BUA and SI), and menopausal status (BUA). Several modifiable dietary factors, such as a diet rich in omega-3 PUFAs and lifestyle factors (i.e., smoking, taking HRT), were shown to determine QUS parameters after a follow-up of two years.
\end{abstract}

\section{Introduction}

Inuit populations live in extreme climatic conditions and exhibit specific lifestyle and dietary habits, in particular their traditional diet that comprises large amounts of fish and marine mammal meat and fat [1]. Few data are available on the determinants of bone fragility in Inuit living in circumpolar regions. Bone fragility significantly increases the risk of osteoporotic fracture following minimal trauma, which may have serious public health consequences (mortality, morbidity, and health care costs), especially when the event occurs at a later age [2].

Studies conducted during the 70's reported that Inuit experience an earlier onset and a greater bone loss with age, compared to U.S. Caucasians [3-6]. Furthermore, cortical bone thickness in Inuit was also reported to be lower than in Caucasians [5-8]. Thickness values follow a decreasing trend from Mongoloid groups of Umnak-Kodiak on the Bering Sea going eastward to Greenland, with a breaking point between Inupiaq and Yupik Inuit [9]. Histological analyses of the femur revealed that the Inuit possesses more osteons per surface unit than U.S. Caucasians, although osteons are similar in size [6]. The osteon remodeling pattern in Inuit also seems to differ from that in other populations $[8,10,11]$. In a descriptive cross-sectional study among peri- and postmenopausal Inuit women from Nuuk (capital of Greenland), Côté et al. reported lower values of bone parameters measured by quantitative ultrasonography (QUS) at the right calcaneus compared to values obtained in southern Québec women. Mean values for broadband ultrasound attenuation (BUA), 
speed of sound (SOS), and the stiffness index (SI) were, respectively, 4\%, 1.4\%, and 9.5\% lower in Greenlandic Inuit women compared to the southern Quebec women [12].

Several hypotheses have been raised to explain the osteological features of Inuit, including their diet rich in animal proteins, phosphorus, and nitrogen and low in calcium [3,4], genetic factors, low sun exposure, and cultural factors [13]. A low dietary calcium intake, smoking, and the chronic use of oral steroids have been identified as major risk factors for low BMD at the calcaneus of Alaska Natives [14]. The shift toward a Western diet was associated with a significant reduction in vitamin D status in Inuit from Nuuk compared to Inuit with a more traditional diet living outside the capital [15], which may have an impact on bone health. The omega-3 PUFAs from marine food, such as eicosapentaenoic acid (EPA) and docosahexaenoic acid (DHA) and an elevated omega3/omega-6 polyunsaturated fatty acids (PUFAs) content ratio in phospholipids of erythrocyte membranes were associated with increased BUA values in Inuit women from Nuuk [16]. In the study by Côté et al., age and plasma concentration of a mono-ortho substituted polychlorinated biphenyl congener (PCB 156), displaying some dioxin-like (DL) activity, was negatively associated with calcaneal QUS parameters in Inuit women from Nuuk, whereas positive associations were noted with body weight, hormone replacement therapy (HRT), and oral contraceptive uses [12].

The technique of bone ultrasound measurement is simple, rapid, noninvasive, nonradioactive, inexpensive, and can be implemented with easy-to-use portable devices [17]. It is especially well suited to assess bone quality/strength in isolated communities, where the measurement of bone mineral density (BMD, $\mathrm{g} / \mathrm{cm}^{2}$ ) by dual-energy X-ray absorptiometry (DXA), the reference method for the diagnosis of osteoporosis according to the World Health Organization [18], cannot be performed. Bone parameters measured by QUS reflect the intrinsic quality and biomechanical properties of bone and provide information complementary to that of $\mathrm{BMD}$ on bone strength [19]. Despite its advantages, the QUS method has seldom been used to estimate bone strength/quality in these remote areas inhabited by Inuit.

The main objective of this study was to identify the predictors of calcaneal QUS parameters measured after a followup of two years in Greenlandic Inuit women participating in a longitudinal study between 2000 and 2002, among a large number of factors recorded at baseline. As a secondary objective, we aimed to identify the determinant factors of bone parameters at baseline in 2000, using a cross-sectional study design.

\section{Methods}

2.1. Population. A descriptive cross-sectional study was conducted during September 2000 in Nuuk (Godthab, Greenland, $64^{\circ} \mathrm{N}$ latitude), home to approximately 14,000 residents, in order to assess bone strength in peri- and postmenopausal Inuit women and identify its determinant factors, with a special focus on exposure to food-chain contaminants. Data collection was previously described by Côté et al. [12]. Inclusion criteria were: being a woman aged between 49 and
64 years and born in Greenland. A random sample of 200 women was drawn from the list of Statistics Greenland, which included 547 women who were potentially eligible. Among the 200 women, 7 died, 11 had moved, and 15 were outside the city at the time of the study (not for medical reasons). Finally, 167 women were invited to participate in the study, at the Primary Health Care Clinic of Queen's Ingrid Hospital in Nuuk. Eight of them refused and six were excluded because of diseases (HIV, mental illness, and influenza). Hence, 153 Inuit women participated in the cross-sectional study [12].

Participants answered a questionnaire to document the most important factors affecting bone health during a faceto-face interview conducted in Danish. The questionnaire was adapted from that of the Mediterranean Osteoporosis Study [20]. Subsequently, the women participated in a clinical session that comprised blood sampling, anthropometric measurements, and QUS parameter determination at the right calcaneus. Out of the 153 participants, 148 had enough plasma collected to allow biochemical and toxicological analyses.

Two years later, from August 26 to September 3, 2002, participants at the first QUS measurement were invited for a second measurement using the same technique and instrument as in 2000. From the 153 participants in 2000, 121 completed the study in 2002. Of the 32 nonparticipants in 2002, three had died, five had moved, eleven could not be reached by telephone, seven refused to participate, and six did not show up for their appointment. Among the 121 Inuit women who had the second QUS measurement, 118 had a sufficient quantity of plasma collected to allow all biochemical and toxicological analyses.

2.2. QUS Measurements. SOS $(\mathrm{m} / \mathrm{s})$ and BUA $(\mathrm{dB} / \mathrm{MHz})$ were measured with the Achilles Lunar water-bath ultrasound instrument (Lunar Corporation, Madison, WI, USA) at the right calcaneus of participants. A research nurse performed all QUS measurements. SI, a linear combination of the two QUS parameters, was calculated automatically by the device according to the manufacturer's formula [SI\% $=(0.67 *$ BUA $)+(0.28 *$ SOS $)-420]$.

The instrument was calibrated daily using the acoustic phantom provided by the manufacturer. In vivo precision was assessed by repeated measurements conducted in 15 subjects: mean coefficients of variation (CV) were $0.8 \%$ for BUA, $0.2 \%$ for SOS, and $1.1 \%$ for SI measurements at baseline [12]. In vivo repeated measures for a 42-year-old woman conducted over a one-year period, prior to beginning the follow-up measurements, using the same equipment, yielded $\mathrm{CV}$ values of $1.4 \%$ for BUA, $0.2 \%$ for SOS, and $1.3 \%$ for SI.

2.3. Anthropometric Measurements. Weight (kg), height, abdominal circumference, and hip circumference $(\mathrm{cm})$ were measured using standardized techniques by research nurses.

\subsection{Laboratory Analyses}

2.4.1. Lipids. Omega-3 and omega-6 polyunsaturated fatty acids (PUFA) were measured in erythrocyte membrane phospholipids by gas liquid chromatography using a HP5890 gas 
chromatograph (Hewlett Packard, Toronto, ON) equipped with a HP8823 capillary column, a 7673A autosampler, and a flame ionization detector (FID). The analyses were performed at the Department of Nutritional Sciences, University of Guelph (Ontario) [12]. Erythrocyte membrane total omega3 PUFAs and total omega-6 PUFAs contents were calculated and expressed as percentages of all fatty acids in membrane phospholipids. Total omega-3 PUFAs refer to the sum of the following fatty acids: alpha-linolenic acid (C18: $3 n-3)$, eicosapentaenoic acid (C20:5n-3), docosapentaenoic acid (C22: $5 n-3)$, docosahexaenoic acid (C22: $6 n-3), \mathrm{C} 18: 4 n-3$, C20: $3 n-3$, C20: $4 n-3$. Total omega-6 PUFAs refer to the sum of linoleic acid (C18: $2 n-6)$, arachidonic acid (C20: $4 n-6)$, C18: 3n-6, C20: $2 n-6$, C20: 3n-6, C22: 2n-6, C22: 4n-6, C22: $5 n-6$.

Plasma cholesterol and triglycerides concentrations $(\mathrm{mmol} / \mathrm{L})$ were determined by standard enzymatic procedures on an AutoAnalyzer II instrument (Technicon Instruments Corporation, Tarrytown, NY).

2.4.2. DL-PCB 156. Concentration of DL-PCB 156 was measured in the plasma of participants using gas chromatography-electron capture detection (GC-ECD). The analyses were performed at the Toxicology Laboratory of the Institut National de Santé Publique de Québec (INSPQ, Canada), which is accredited under ISO 17025 by the Standards Council of Canada. The analytical method was described by Côté et al. [12]. CV based on repeated analysis of a standard reference material (SRM 1589, $n=15$ ) was $18.5 \%$; the percentage of detection was $100 \%$ and the detection limit was $0.02 \mu \mathrm{g} / \mathrm{L}$ [12].

2.5. Questionnaire. A questionnaire was administered to document sociodemographic variables (date and place of birth), lifestyle habits (smoking, yes/no; leisure time physical activity (LPA), inactive/active, yes/no; dairy product consumption (milk, cheese, yogurt) per day and during the last week, yes/no; calcium supplementation during the last month, yes/no; sun exposure over the majority of the body during last year, yes/no), gynaecological history (menopausal status, postmenopausal/nonmenopausal; parity, yes/no; total duration of breastfeeding (months); oral contraceptive use in the past, yes/no; HRT use, yes/no), medical history (major diseases), and personal history of fractures during adulthood (yes/no).

Women were considered postmenopausal if they had no menstrual period for one year before their recruitment in the study or if they had a bilateral oophorectomy for more than six months and/or a level of folliculo-stimulating hormone $(\mathrm{FSH})>40 \mathrm{IU} / \mathrm{L}$.

LPA was documented as the weekly frequency of physical activity during leisure time lasting 20-30 minutes, averaged over the last three months [21]. The LPA variable was dichotomised with the inactive-low activity category corresponding to $0-2$ times/week of LPA and the active category to LPA frequency $\geq 3$ times/week.

The use of certain drugs during the last year (corticosteroids, heparin, Dilantin, Prednisone, and chemotherapy) and some medical conditions (Cushing's disease, rheumatoid arthritis, bone cancer, gastrectomy, renal or hepatic failure, and thyroid and parathyroid diseases) that are linked to bone loss constitute causes of secondary osteoporosis (CSO) [2]. CSO were deemed present if the participant answered positively to one of the elements listed above.

2.6. Statistical Analyses. Descriptive statistics (mean, standard deviation, minimum, maximum for quantitative variables and numbers, and \% per modality for categorical variables) were presented for the participants who participated in QUS measurements in 2000 and 2002. Comparisons of characteristics between participants in both QUS measurements and those who attended only the first measurement were carried out using the Student's $t$-test for continuous variables. We tested differences between groups for categorical variables using the $\chi^{2}$ test (if conditions were met) or the Fisher's exact test.

Pearson correlation coefficients were computed to test intercorrelations among QUS parameters. All variables documented at baseline were investigated if they were correlated with QUS parameters measured in 2000. Variables with a $P$ value $\leq 0.20$ in simple regression were retained and used as "candidate" variables in the predictive models.

Collinearity between "candidate" variables and the predictive models was investigated and redundant variables were removed. Box-Cox procedures were used to resolve problems encountered with the hypotheses of normality and/or homoscedasticity in the multiple linear regression models for the dependent variables SOS and SI, which were subsequently log-transformed.

Firstly, the variables documented in 2000 and related to bone quality were considered for inclusion in predictive models of QUS parameters measured concomitantly. Secondly, the same variables were considered for inclusion in predictive models of QUS parameters measured in 2002. QUS parameters determined at baseline were also considered for inclusion in the latter models. Variables were automatically selected using the stepwise method ( $P$-value $=0.10$ to enter and $P$-value $=0.15$ to exit).

We also calculated differences $(\Delta)$ in QUS parameters between the second (2002) and the first (2000) measurements for each participant, according to the following formula: $\Delta$ QUS $=$ QUS $_{\text {year } 2002}-$ QUS $_{\text {year 2000. }}$. The percent change in QUS parameters that occurred over the two-year period was calculated as follows: $\Delta$ QUS $\%=\left(\Delta \mathrm{QUS} / \mathrm{QUS}_{\text {year 2000 }}\right) *$ 100.

A $P$ value of $<0.05$ in a bilateral situation is considered statistically significant. All statistical analyses were performed using the SAS Version 9.2 software (SAS Institute Inc., Cary, NC, USA).

2.7. Approval of the Research Project. The project was approved by the Commission for Scientific Research in Greenland (Denmark), by the Ethical Committee of the Greenlandic Health Commission (Denmark), and by the Research Ethics Committees of the Hôpital Saint-François d'Assise (CHUQ, Québec, Canada). Participation in the study was voluntary and a consent form was signed by each participant. All information concerning the participants was kept strictly confidential. 


\section{Results}

3.1. Characteristics of the Participants. The characteristics of the 118 participants to both QUS measures are presented in Table 1. At the time of recruitment (year 2000), our participants were between 49 and 64 years old, predominantly postmenopausal, sedentary, smokers, and had had children. Few participants claimed to have used oral contraceptives in the past and among postmenopausal women, few had taken HRT. A limited number of participants had sun exposure during the last year and were taking calcium supplements. All nine fracture cases were wrist fractures; one woman with wrist fracture also reported a vertebral fracture in adulthood. A third of Inuit women (41/118) had a small stature (i.e., $<153 \mathrm{~cm}$ ), a condition that can be associated with osteoporosis [22]. The majority of participants (83/118) had an abdominal circumference $\geq 88 \mathrm{~cm}$, which defines abdominal obesity in women [23], a condition associated with an increased risk of developing serious health problems such as type II diabetes, coronary heart disease, and hypertension. Regarding the body mass index (BMI) [23], only 37/118 participants had normal values (between 18.5 and $24.9 \mathrm{~kg} / \mathrm{m}^{2}$ ), 3/118 were underweight $\left(<18.5 \mathrm{~kg} / \mathrm{m}^{2}\right), 42 / 118$ were overweight $(25.0-$ $\left.29.9 \mathrm{~kg} / \mathrm{m}^{2}\right), 20 / 118$ were obese $\left(30.0-34.9 \mathrm{~kg} / \mathrm{m}^{2}\right)$, and $16 / 118$ were obese morbid $\left(\geq 35 \mathrm{~kg} / \mathrm{m}^{2}\right)$. No difference was observed between the characteristics of the 30 women who participated only in the first QUS measurement in 2000 and those of the 118 participants who attended both measurements in 2000 and 2002 (Table 1).

3.2. Changes in QUS Parameters between 2000 and 2002. Mean annual differences $( \pm \mathrm{SD})$ in QUS parameters were $-2.38 \mathrm{~m} / \mathrm{s}( \pm 5.25)$ for SOS, $-0.78 \mathrm{~dB} / \mathrm{MHz}( \pm 3.16)$ for BUA, and $-1.18 \%( \pm 2.77)$ for SI. Mean percent changes over the two-year interval between QUS parameter measurements were $-0.31 \%( \pm 0.69)$ for SOS, $-1.35 \%( \pm 5.95)$ for BUA, and $-2.84 \%( \pm 7.12)$ for SI. Results from paired tests indicate that QUS parameter changes that occurred between 2000 and 2002 were statistically significant (for $\triangle$ SOS: Student's $t$-test, $P<0.0001$; sign test, $P=0.0004$, for $\Delta B U A$; Student's $t$-test $P=0.0088$; sign test, $P=0.0329$; for SI: Student's $t$-test and sign test, $P<0.0001)$.

Based on $\Delta$ SI values, two thirds of participants (77/118) experienced a decrease over two years $(\Delta S$ S between -18 and $-1), 11 \%(13 / 118)$ had no change $(\Delta \mathrm{SI}=0)$, while $24 \%(28 / 118)$ exhibited improved bone quality $(\Delta$ SI between +1 and +29$)$. QUS parameters determined in 2002 were all significantly and positively correlated to the initial measurements performed in $2000\left(\right.$ SOS $(\log )_{\text {year } 2000}$ with SOS $(\log )_{\text {year } 2002}$ : $r=0.89$ BUA $_{\text {year } 2000}$ with BUA $_{\text {year 2002 }}: r=0.81$; and SI $(\log )_{\text {year } 2000}$ with SI $(\log )_{\text {year 2002 }}: r=0.90$, all $P$ values $<0.0001)$.

3.3. Determinants of QUS Parameters Measured in 2000 (Table 2). QUS measurements obtained in 2000 were determined by four or five factors, depending on the QUS parameter. Age was the statistically significant determinant of lower QUS values $\left(\mathrm{SOS}_{\text {year } 2000}(\log ), \mathrm{BUA}_{\text {year 2000 }}\right.$, and SI $\left.\mathrm{year} 2000(\log )\right)$. Three factors were statistically significant determinants of higher
QUS values: body weight $\left(\mathrm{SOS}_{\text {year 2000 }}(\mathrm{log}), \mathrm{BUA}_{\text {year 2000, }}\right.$ $\left.\mathrm{SI}_{\text {year } 2000}(\log )\right)$, height $\left(\mathrm{BUA}_{\text {year } 2000}\right.$ and $\left.\mathrm{SI}_{\text {year } 2000}(\log )\right)$, and past HRT use $\left(\mathrm{SI}_{\text {year } 2000}(\mathrm{log})\right)$. Age, body weight, and height explained together $82.4 \%, 91.6 \%$, and $93.3 \%$ of the variance explained for $\mathrm{SOS}_{\text {year } 2000}(\log ), \mathrm{BUA}_{\text {year } 2000}$, and $\mathrm{SI}_{\text {year } 2000}$ (log), respectively.

3.4. Predictors of QUS Parameters Measured in 2002 (Table 3). Models for QUS measurements obtained in 2002 each comprised five factors. For all parameters, the QUS measurement of 2000 was the main determinant of the value measured in 2002, representing 96.3\%, 91.9\%, and $95.2 \%$ of the variance explained for SOS $(\log )_{\text {year 2002 }}, \mathrm{BUA}_{\text {year 2002 }}$, and SI $(\log )_{\text {year 2002, }}$ respectively. Two other factors were statistically significant predictors of higher QUS values: past HRT use $\left(\mathrm{SOS}_{\text {year } 2002}(\log ), \mathrm{BUA}_{\text {year } 2002}\right.$ and $\left.\mathrm{SI}_{\text {year 2002 }}(\log )\right)$ and the omega-3/omega-6 PUFA content ratio in erythrocyte membranes $\left(\mathrm{BUA}_{\text {year } 2002}\right.$ and $\left.\mathrm{SI}_{\text {year } 2002}(\log )\right)$. Smoking status was a statistically significant predictor of lower values of all QUS parameters $\left(\right.$ SOS $_{\text {year } 2002}(\log ), \mathrm{BUA}_{\text {year } 2002}$ and $\mathrm{SI}_{\text {year } 2002}$ $(\log ))$ and menopausal status of lower BUA year 2002 values.

\section{Discussion}

This longitudinal study identifies determinants of bone strength/quality, as measured by QUS parameters, in periand postmenopausal Greenlandic Inuit women. We found that after a two-year follow-up, lower QUS measures were predicted by smoking and postmenopausal status, whereas past HRT use and an elevated omega-3/omega-6 PUFA content ratio in erythrocyte membranes is predictive of higher QUS values. Baseline QUS measures, the strongest determinants of QUS measures after a two-year follow-up, were themselves determined by age, past HRT use, body weight, and height.

Most predictors of QUS values identified in the present study were also shown to influence bone quality parameters in other populations. Several studies have reported that QUS parameters measured by ultrasound at the calcaneus decrease significantly with age [12, 24-33]. Height [28, 29] and body weight $[12,27-29,32-34]$ were also often found to be positively correlated to QUS parameters measured at the heel. According to Babaroutsi et al. (2005), overweight $\left(\mathrm{BMI} \geq 25 \mathrm{~kg} / \mathrm{m}^{2}\right)$ or obese $\left(\mathrm{BMI} \geq 30 \mathrm{~kg} / \mathrm{m}^{2}\right)$ women display significantly higher BUA values (measured with a SAHARA instrument) than women with normal BMI, regardless of their age group [34]. While obesity seems protective against osteoporosis, results from recent epidemiologic and clinical studies indicate that a high body fat level might constitute a risk factor for osteoporosis and fragility fractures [35]. The body fat mass was not measured in our participants. In our study, almost a third of women were considered obese according to the international criteria of BMI. While BMI is an index used frequently in the general population, the measure of obesity based on BMI is not appropriate among Inuit, due to their higher sitting height [36]. The impact of obesity on metabolic indicators such as plasma lipids and blood pressure in Inuit is lower than in other Euro-Canadian populations $[36,37]$. 
TABLE 1: Characteristics of Inuit women.

\begin{tabular}{|c|c|c|c|}
\hline $\begin{array}{l}2002 \text { measurements } \\
(N=118)\end{array}$ & Mean \pm SD & Range & \\
\hline $\operatorname{SOS}(\mathrm{m} / \mathrm{s})$ & $1518.43 \pm 22.66$ & $1468-1600$ & \\
\hline $\mathrm{BUA}(\mathrm{dB} / \mathrm{MHz})$ & $106.41 \pm 10.56$ & $80-144$ & \\
\hline SI $(\%)$ & $76.07 \pm 12.11$ & $50-124$ & \\
\hline 2000 measurements & $\begin{array}{l}\text { Participation in } 2000 \text { and } 2002 \\
(N=118)\end{array}$ & $\begin{array}{c}\text { Nonparticipation in } 2002 \\
(N=30)\end{array}$ & Comparison \\
\hline QUS parameters & $\begin{array}{l}\text { Mean } \pm \text { SD } \\
\text { Range }\end{array}$ & $\begin{array}{l}\text { Mean } \pm \text { SD } \\
\text { Range }\end{array}$ & $\begin{array}{l}\text { Student's } t \text {-test } \\
P \text { value }^{\mathrm{a}}\end{array}$ \\
\hline $\operatorname{sOS}(\mathrm{m} / \mathrm{s})$ & $\begin{array}{c}1523.19 \pm 23.12 \\
1464-1595\end{array}$ & $\begin{array}{c}1520.90 \pm 37.01 \\
1463-1592\end{array}$ & 0.7479 \\
\hline $\mathrm{BUA}(\mathrm{dB} / \mathrm{MHz})$ & $\begin{array}{c}107.96 \pm 9.61 \\
84-136\end{array}$ & $\begin{array}{c}108.43 \pm 15.08 \\
82-140\end{array}$ & 0.8703 \\
\hline SI $(\%)$ & $\begin{array}{c}78.42 \pm 11.85 \\
51-117 \\
\end{array}$ & $\begin{array}{c}78.10 \pm 19.71 \\
47-116\end{array}$ & 0.9319 \\
\hline \multicolumn{4}{|l|}{ Other factors } \\
\hline Age (years) & $\begin{array}{c}55.25 \pm 4.22 \\
49-64\end{array}$ & $\begin{array}{c}56.13 \pm 4.90 \\
49-63\end{array}$ & 0.3261 \\
\hline Total breastfeeding duration (months) & $\begin{array}{c}32.21 \pm 40.10 \\
0-216\end{array}$ & $\begin{array}{c}25.33 \pm 29.20 \\
1-108\end{array}$ & 0.3797 \\
\hline Height $(\mathrm{cm})$ & $\begin{array}{c}155.89 \pm 6.66 \\
142-171\end{array}$ & $\begin{array}{c}156.27 \pm 6.44 \\
145-171\end{array}$ & 0.7810 \\
\hline Body weight (kg) & $\begin{array}{c}67.62 \pm 14.46 \\
37-99\end{array}$ & $\begin{array}{c}66.50 \pm 17.49 \\
36-99\end{array}$ & 0.7164 \\
\hline Ratio abdominal/hip circumference & $\begin{array}{c}0.93 \pm 0.07 \\
0.78-1.09\end{array}$ & $\begin{array}{c}0.94 \pm 0.07 \\
0.77-1.10\end{array}$ & 0.2672 \\
\hline Total cholesterol (mmol/L) & $\begin{array}{c}2.60 \pm 0.48 \\
1.73-4.67\end{array}$ & $\begin{array}{c}2.56 \pm 0.54 \\
1.38-4.24\end{array}$ & 0.6783 \\
\hline Total triglycerides $(\mathrm{mmol} / \mathrm{L})$ & $\begin{array}{l}1.64 \pm 1.34 \\
0.44-13.36\end{array}$ & $\begin{array}{c}1.53 \pm 0.84 \\
0.61-3.87\end{array}$ & 0.5939 \\
\hline Omega-3 PUFA (\%) & $\begin{array}{c}13.97 \pm 4.63 \\
4.78-27.56\end{array}$ & $\begin{array}{c}13.78 \pm 5.03 \\
6.15-25.18\end{array}$ & 0.8476 \\
\hline Omega-6 PUFA (\%) & $\begin{array}{r}22.79 \pm 4.47 \\
12.44-31.45\end{array}$ & $\begin{array}{c}22.18 \pm 4.92 \\
10.87-29.55\end{array}$ & 0.5106 \\
\hline Ratio omega-3/omega-6 PUFA & $\begin{array}{c}0.68 \pm 0.37 \\
0.17-2.21\end{array}$ & $\begin{array}{c}0.70 \pm 0.44 \\
0.21-2.32\end{array}$ & 0.7657 \\
\hline DL-PCB $156(\mu \mathrm{g} / \mathrm{L})$ & $\begin{array}{c}0.70 \pm 0.35 \\
0.13-2.12 \\
0.62^{\mathrm{b}}\end{array}$ & $\begin{array}{c}0.86 \pm 0.56 \\
0.22-2.31 \\
0.72^{\mathrm{b}} \\
\end{array}$ & 0.1450 \\
\hline & $N(\%)$ & $N(\%)$ & $P$ value $^{\mathrm{a}}$ \\
\hline Menopausal status & 118 & 30 & \\
\hline Postmenopausal & $107(90.7)$ & $26(86.7)$ & $0.5062^{\mathrm{c}}$ \\
\hline Nonmenopausal & $11(9.3)$ & $4(13.3)$ & \\
\hline Parity & 118 & 30 & \\
\hline Yes & $108(91.5)$ & $30(100)$ & $0.2139^{c}$ \\
\hline No & $10(8.5)$ & $0(0)$ & \\
\hline Personal history of fracture & 118 & 30 & \\
\hline Yes & $9(7.6)$ & $4(13.3)$ & $0.3002^{c}$ \\
\hline No & $109(92.4)$ & $26(86.7)$ & \\
\hline
\end{tabular}


TABLe 1: Continued.

\begin{tabular}{|c|c|c|c|}
\hline Causes of secondary osteoporosis (CSO) & 118 & 30 & \multirow{3}{*}{$1.0000^{\mathrm{C}}$} \\
\hline Yes & $12(10.2)$ & $3(10)$ & \\
\hline No & $106(89.8)$ & $27(90)$ & \\
\hline Calcium supplement use & 118 & 30 & \multirow{3}{*}{$0.4679^{\mathrm{c}}$} \\
\hline Yes & $12(10.2)$ & $1(3.3)$ & \\
\hline No & $106(89.8)$ & $29(96.7)$ & \\
\hline HRT use & 118 & 30 & \multirow{3}{*}{$0.7272^{\mathrm{c}}$} \\
\hline Yes & $10(8.5)$ & $3(10)$ & \\
\hline No & $108(91.5)$ & $27(90)$ & \\
\hline Oral contraceptive use & 118 & 30 & \multirow{3}{*}{$0.9865^{\mathrm{d}}$} \\
\hline Yes & $47(39.8)$ & $12(40)$ & \\
\hline No & $71(60.2)$ & $18(60)$ & \\
\hline Leisure physical activity (LPA) & 118 & 30 & \multirow{3}{*}{$0.7415^{\mathrm{c}}$} \\
\hline Active & $12(10.2)$ & $4(13.3)$ & \\
\hline Inactive or little activity & $106(89.8)$ & $26(86.7)$ & \\
\hline Smoking status & 118 & 30 & \multirow{3}{*}{$0.2059^{\mathrm{d}}$} \\
\hline Yes & $85(72)$ & $25(83.3)$ & \\
\hline No & $33(28)$ & $5(16.7)$ & \\
\hline Sun exposure & 118 & 30 & \multirow{3}{*}{$0.7987^{\mathrm{d}}$} \\
\hline Yes & $25(21.2)$ & $7(23.3)$ & \\
\hline No & $93(78.8)$ & $23(76.7)$ & \\
\hline Alcohol intake & 118 & 30 & \multirow{3}{*}{$0.6026^{\mathrm{d}}$} \\
\hline Yes & $73(61.9)$ & $17(56.7)$ & \\
\hline No & $45(38.1)$ & $13(43.3)$ & \\
\hline Consumption of dairy products & 118 & 30 & \multirow{3}{*}{$1.0000^{c}$} \\
\hline Yes $(\geq 1 /$ jour $)$ & $106(89.8)$ & $27(90)$ & \\
\hline No (0/jour) & $12(10.2)$ & $3(10)$ & \\
\hline
\end{tabular}

${ }^{\mathrm{a}}$ Comparison between the participants $(n=118)$ and the nonparticipants $(n=30)$ to the second QUS measurement $(2002) ;{ }^{\mathrm{b}} \mathrm{Geometric}$ mean; ${ }^{\mathrm{c}}$ Fisher's exact test; ${ }^{\mathrm{d}}$ Chi square test.

Several studies have reported that QUS parameters measured at the calcaneus significantly decrease in women going through menopause $[24,25,30]$. Smoking was also identified as a risk factor for decreased bone quality as determined by ultrasonography at the heel $[26,27,31,38,39]$. Current or past HRT use has been positively associated with QUS parameters $[12,26]$. Women participating in the Epidemiological Study on the Prevalence of Osteoporosis, who took HRT for more than a year, had significantly higher SI values compared to those of nonusers, and differences remained significant even 20 years after menopause [27]. HRT use for more than 3 years was associated with higher QUS values compared to those measured in nonusers [40]. In the EPIC-Norfolk cohort, BUA values (measured with a CUBA instrument) in women with past HRT use exceeded those of nonusers by an average of $5 \mathrm{~dB} / \mathrm{MHz}$ [39].

Results of our predictive modelling approach corroborate the positive association previously reported in an explanatory study between increased omega-3/omega-6 PUFA content ratio in erythrocyte membranes and BUA values in Greenlandic Inuit women [16]. The content of omega-3 PUFA in erythrocyte membranes reflects dietary omega-3 PUFA intake. EPA and DHA content of erythrocyte membranes increased with the frequency of 3 or more fish meals per week among the Inuit women of Nuuk $(P=0.0018)$ [16]. Results from in vitro studies, laboratory animal experiments, and human studies suggest a beneficial effect of omega-3 PUFAs and low omega-6/omega-3 PUFA ratio on bone health and osteoporosis [41-43].

Côté et al. previously reported that the plasma concentration of DL-PCB 156 was negatively associated with calcaneal QUS parameters in 153 Inuit women from Nuuk [12]. In the current cross-sectional and longitudinal study, DL-PCB 156 concentration measured at baseline was not a determinant of QUS parameters values measured concomitantly or after a two-year follow-up. Also in contrast to the previous results [12], past oral contraceptive use was not found to be a significant predictive factor of QUS parameters. Côté et al.s study was explanatory and focused exclusively on organochlorine compounds as the main exposure variable; only four adjustment factors (age, body weight, oral contraceptive, and HRT use) were considered in the multivariate models.

Some determinant factors were associated with either BUA or SOS, but not with both parameters. Height was 
TABLE 2: Determinants of QUS parameters at the first measurement (2000).

\begin{tabular}{|c|c|c|c|}
\hline \multicolumn{4}{|l|}{ Model $^{\mathrm{a}}$} \\
\hline \multicolumn{4}{|l|}{$N=118$} \\
\hline \multicolumn{4}{|l|}{ SOS $(\log )_{\text {year } 2000}(\mathrm{~m} / \mathrm{s})^{\mathrm{b}}$} \\
\hline \multicolumn{4}{|l|}{$R^{2}=0.2709$} \\
\hline Variables & $R^{2}$ partial & $\beta$ coefficient (SE) & $P$ value \\
\hline Intercept & - & $7.34480(0.04531)$ & $<0.0001$ \\
\hline Height $(\mathrm{cm})$ & 0.1207 & $0.00035(0.00022)$ & 0.1077 \\
\hline Age (years) & 0.0835 & $-0.00093(0.00030)$ & 0.0025 \\
\hline HRT use (Yes/No) & 0.0281 & $0.00862(0.00456)$ & 0.0610 \\
\hline Weight (kg) & 0.0190 & $0.00027(0.00011)$ & 0.0172 \\
\hline Ratio waist circumference/hip circumference & 0.0196 & $-0.04157(0.02396)$ & 0.0856 \\
\hline \multicolumn{4}{|l|}{$\begin{array}{c}\text { BUA }_{\text {year } 2000}(\mathrm{~dB} / \mathrm{MHz})^{\mathrm{b}} \\
R^{2}=0.4029\end{array}$} \\
\hline Variables & $R^{2}$ partial & $\beta$ coefficient (SE) & $P$ value \\
\hline Intercept & - & $48.71032(20.93768)$ & 0.0218 \\
\hline Height $(\mathrm{cm})$ & 0.2147 & $0.41009(0.11485)$ & 0.0005 \\
\hline Weight (kg) & 0.1234 & $0.24673(0.05054)$ & $<0.0001$ \\
\hline Age (years) & 0.0309 & $-0.40096(0.17109)$ & 0.0209 \\
\hline Calcium supplements use (Yes/No) & 0.0185 & $4.03632(2.34922)$ & 0.0885 \\
\hline HRT use (Yes/No) & 0.0155 & $4.45645(2.61774)$ & 0.0915 \\
\hline
\end{tabular}

\begin{tabular}{lccc}
\hline SI $(\log )_{\text {year } 2000}(\%)^{\mathrm{b}}$ & & & \\
$\quad R^{2}=0.3657$ & $R^{2}$ partial & $\beta$ coefficient (SE) & \\
\hline Variables & - & $3.56182(0.33487)$ & $<$ value \\
\hline Intercept & 0.2065 & $0.00664(0.00184)$ & 0.0001 \\
Height $(\mathrm{cm})$ & 0.0734 & $0.00311(0.00082)$ & 0.0005 \\
Weight $(\mathrm{kg})$ & 0.0614 & $-0.00840(0.00275)$ & 0.0002 \\
Age (years) & 0.0243 & $0.08752(0.04208)$ & 0.0028 \\
HRT use (Yes/No) & & & 0.0398 \\
\hline
\end{tabular}

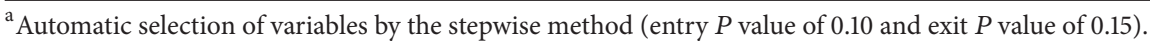

"Candidate" variables in the predictive model were age, height, body weight, waist circumference/hip circumference ratio, ratio omega-3/omega-6 PUFA (or \% omega-6 PUFA), DL-PCB 156, total breastfeeding duration, menopausal status, oral contraceptive use, HRT use, smoking status, calcium supplement use, sun exposure, and consumption of dairy products ("candidate" variables were measured at baseline (year 2000) and all these variables in simple linear regression

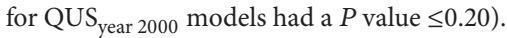

${ }^{b}$ The same determinants were identified in a predictive model that comprised a greater number of "candidate" variables, for example, variables listed in note ${ }^{\text {a }}$ plus eight variables with a $P$ value $>0.20$ in simple regression models. This model included only 101 participants for whom dataset was complete. "Candidate" variables in this predictive model were age, height, body weight, waist circumference/hip circumference ratio, \% omega-6 PUFA, DL-PCB 156, total breastfeeding duration, menopausal status, oral contraceptive use, HRT use, smoking status, calcium supplement use, sun exposure, consumption of dairy products, and total cholesterol, total triglycerides, \% omega-3 PUFA, personal history of fracture, LPA, CSO, parity, and alcohol intake. All "candidate" variables were measured at baseline (year 2000).

a statistically significant determinant of BUA but not SOS at baseline (year 2000). Omega-3/omega-6 PUFA ratio and menopausal status were determinants of BUA but not SOS at follow-up (year 2002). SOS is the ratio of propagation distance to the pulse transit time across bone. BUA is the rate of attenuation in the acoustic energy across a broad range of frequency; this attenuation is due to the absorption and scattering of ultrasound in the bone, marrow, and soft tissue. Although both SOS and BUA parameters provide information on bone strength, they do not reflect exactly the same bone properties (microarchitectural parameters, bone geometry and composition, or elastic properties) [19, 44]. This may explain the differences observed among the identified predictors. SI, a composite parameter that combines BUA and SOS, appears more useful than the individual parameters for a global evaluation of bone strength determinants.

QUS can evaluate quantitative factors known to be associated with bone strength that are not assessed by DXA, such as cortical thickness, microarchitecture (bone geometry, trabecular orientations), material properties (i.e., bone size, bone mineral content, degree of mineralization, and porosity), and bone elasticity $[19,44]$. Bone strength and elasticity determine bone resistance to fractures. Recent studies reported that bone parameters measured by QUS at the calcaneus can predict fractures as effectively as DXA in postmenopausal women and men aged 65 years and older [18, 45]. Values of QUS parameters are generally lower in osteoporotic patients than in healthy subjects [46]. However, it remains unclear 
TABLE 3: Predictors of QUS parameters at the second measurement (2002).

\begin{tabular}{|c|c|c|c|}
\hline Model $^{\mathrm{a}}$ & & & \\
\hline$N=118$ & & & \\
\hline SOS $(\log )_{\text {year } 2002}(\mathrm{~m} / \mathrm{s})^{\mathrm{b}}$ & & & \\
\hline$R^{2}=0.8306$ & & & \\
\hline Variables & $R^{2}$ partial & $\beta$ coefficient (SE) & $P$ value \\
\hline Intercept & - & $1.19773(0.32028)$ & 0.0003 \\
\hline $\operatorname{SOS}(\log )_{\text {year } 2000}(\mathrm{~m} / \mathrm{s})$ & 0.7997 & $0.84241(0.04380)$ & $<0.0001$ \\
\hline Smoking status (Yes/No) & 0.0108 & $-0.00410(0.00132)$ & 0.0024 \\
\hline HRT use (Yes/No) & 0.0102 & $0.00609(0.00219)$ & 0.0063 \\
\hline Height $(\mathrm{cm})$ & 0.0052 & $-0.00019(0.00009)$ & 0.0520 \\
\hline Age (years) & 0.0047 & $-0.00027(0.00015)$ & 0.0805 \\
\hline $\mathrm{BUA}_{\text {year } 2002}(\mathrm{~dB} / \mathrm{MHz})^{\mathrm{c}}$ & & & \\
\hline$R^{2}=0.7092$ & & & \\
\hline Variables & $R^{2}$ partial & $\beta$ coefficient (SE) & $P$ value \\
\hline Intercept & - & $19.77795(7.15003)$ & 0.0066 \\
\hline BUA $_{\text {year } 2000}(\mathrm{~dB} / \mathrm{MHz})$ & 0.6517 & $0.82784(0.05972)$ & $<0.0001$ \\
\hline Smoking status (Yes/No) & 0.0178 & $-3.53459(1.21960)$ & 0.0045 \\
\hline Ratio omega-3/omega-6 PUFA & 0.0199 & $4.29757(1.45547)$ & 0.0038 \\
\hline HRT use (Yes/No) & 0.0090 & $4.28491(2.01686)$ & 0.0358 \\
\hline Menopausal status (Yes/No) & 0.0108 & $-3.83486(1.87776)$ & 0.0435 \\
\hline SI $(\log )_{\text {year } 2002}(\%)^{\mathrm{d}}$ & & & \\
\hline$R^{2}=0.8410$ & & & \\
\hline Variables & $R^{2}$ partial & $\beta$ coefficient (SE) & $P$ value \\
\hline Intercept & - & $0.75016(0.23022)$ & 0.0015 \\
\hline SI $(\log )_{\text {year } 2000}(\%)$ & 0.8005 & $0.85902(0.04289)$ & $<0.0001$ \\
\hline Smoking status (Yes/No) & 0.0140 & $-0.05410(0.01377)$ & 0.0001 \\
\hline Ratio omega-3/omega-6 PUFA & 0.0119 & $0.05795(0.01677)$ & 0.0008 \\
\hline HRT use (Yes/No) & 0.0092 & $0.05307(0.02183)$ & 0.0166 \\
\hline Age (years) & 0.0055 & $-0.00313(0.00160)$ & 0.0523 \\
\hline
\end{tabular}

${ }^{a}$ Automatic selection of variables by the stepwise method (entry $P$ value of 0.10 and exit $P$ value of 0.15 ).

"Candidate" variables in the predictive model were QUS year 2000, age, height, body weight, waist circumference/hip circumference ratio, ratio omega-3/omega-6 PUFA, DL-PCB 156, total breastfeeding duration, menopausal status, oral contraceptive use, HRT use, smoking status, calcium supplement use, sun exposure, and consumption of dairy products ("candidate" variables were measured at baseline, year 2000).

${ }^{\mathrm{b}}$ The same predictive variables were identified in a predictive model that comprised a greater number of "candidate" variables: SOS (log) year 2000, age, height, body weight, waist circumference/hip circumference ratio, \% omega-6 PUFA, DL-PCB 156, total breastfeeding duration, menopausal status, oral contraceptive use, HRT use, smoking status, calcium supplement use, sun exposure, consumption of dairy products, and total cholesterol, total triglycerides, \% omega-3 PUFA, personal history of fracture, LPA, CSO, parity, and alcohol intake. All "candidate" variables were measured at baseline (year 2000). This model included only 101 participants for whom dataset was complete.

${ }^{c}$ The same predictive variables were identified when all "candidate" variables were included in the predictive model (BUA $\mathrm{year}_{2000}$ and the other variables listed in note $\left.{ }^{\mathrm{b}} ; n=101\right)$.

When \% omega-3 PUFA and \% omega-6 PUFA were included as "candidate" variables instead of the omega-3/omega-6 PUFA ratio, the \% omega-3 PUFA was significant $\left(P=0.0049 ; R^{2}\right.$ partial $\left.=0.0202\right)$. The model $\left(R^{2}=0.7080\right)$ was $B_{\text {UUA }}$ year 2002 $=18.50058+0.82080 \mathrm{BUA}_{\text {year } 2000}-3.42455$ smoking status + $0.33554 \%$ omega-3 PUFA + 4.17829HRT use -3.61551 menopausal status.

${ }^{\mathrm{d}}$ The same predictive variables were identified when all "candidate" variables for the predictive model [SI $(\log )_{\text {year } 2000}$ and the other variables given in note $\mathrm{b}^{\mathrm{b}}$ ] were used $(n=101)$.

When \% omega-3 PUFA and \% omega-6 PUFA were included as "candidate" variables instead of the omega-3/omega-6 PUFA ratio, the \% omega-3 PUFA was significant $\left(P=0.0013 ; R^{2}\right.$ partial $\left.=0.0113\right)$. The model $\left(R^{2}=0.8397\right)$ was SI $(\log )_{\text {year } 2002}=0.75160+0.85030$ SI $(\log )_{\text {year } 2000}-0.05201$ smoking status + $0.00441 \%$ omega-3 PUFA +0.05289 HRT use -0.00290 age. 
as to what elements evaluated by QUS truly correlate with measures of bone strength; a fundamental understanding is still lacking [47]. Differences exist also between the various QUS devices and skeletal sites measured [18].

4.1. Considerations Regarding Our Study. The main advantage of our study is its longitudinal design with repeated measures of QUS parameters two years apart. Causal inference is supported by the fact that exposure factors were measured in 2000, prior to QUS parameter measurements in 2002. In addition, the type of sampling and recruitment allows for generalising our results to the population of Inuit women aged 49 to 64 years living in Nuuk (Greenland). Our study also benefits from the inclusion of a relatively large number of factors known to be associated with bone strength.

Measurement biases in QUS parameters are relatively unlikely. None of the participants had suffered a fracture and none showed oedema of the foot. The temperature of the water bath was constantly monitored and that of the foot verified prior to conducting measurements, because it is known that the temperature of the skin and soft tissue may affect SOS values [18]. Furthermore, data collection in the field (ultrasound measurements, anthropometric measurements) and blood sampling were performed by research nurses using standardized techniques. All laboratory analyses were carried out using standardized methods.

However, our study has some limitations. From the outset, the number of participants of the first QUS measure was low. The percentage of participants lost to follow-up in 2002 was important (20\%), which might lead to a selection bias. However, being lost to follow-up was neither related to bone fragility nor to exposures. Women who did not participate in the second bone measurement in 2002 were not different from those who participated in both measures for all factors investigated.

Some potential predictors of bone quality documented by questionnaires may not have been properly assessed. For example, regarding exposure to sunlight as a source of vitamin $\mathrm{D}$, only one question was asked to inquire about any occurrence of whole-body exposure during the last year. The frequency of sun bathing per week, the time of day, or the season during which exposure occurred [48] were not assessed, which may have led to exposure misclassification. The assessment of LPA considered only the frequency of activities; no information was collected on the type of activity performed or its intensity. COS comprised several different diseases and medications [2], without the possibility of distinguishing between different categories because the numbers were too small in each of them. Finally, questions on dietary supplementation covered only calcium and not vitamin D supplements.

In conclusion, even over a short period of two years, significant decreases in QUS parameters were observed in this group of mostly postmenopausal Inuit women. QUS parameters measured two years apart were predicted by a number of modifiable factors, including dietary and lifestyle habits. Reducing smoking prevalence and promoting the traditional diet rich in omega-3 PUFA may improve bone strength of women in this population.

\section{Conflict of Interests}

The authors declare that there is no conflict of interests regarding the publication of this paper.

\section{Acknowledgments}

The authors would like to thank the Inuit women of Nuuk who participated in this research project and the medical and health care professionals from the Center of Primary Health Care Queen's Ingrid Hospital for their assistance in collecting data. This study was funded by the Commission for Scientific Research in Greenland and by Helsefonden from Denmark. ACP is the recipient of a Doctoral Training Award from the Fonds de Recherche du Québec-Santé and a doctoral scholarship from Nasivvik-Centre for Inuit Health and Changing Environments.

\section{References}

[1] S. G. Donaldson, J. Van Oostdam, C. Tikhonov et al., "Environmental contaminants and human health in the Canadian Arctic," Science of the Total Environment, vol. 408, no. 22, pp. 5165-5234, 2010

[2] The Journal of The North American, "Menopause Society, Management of osteoporosis in postmenopausal women: 2010 Position Statement of the North American Menopause Society," Menopause, vol. 17, no. 1, pp. 25-54, 2010.

[3] R. B. Mazess and W. Mather, "Bone mineral content of North Alaskan Eskimos," American Journal of Clinical Nutrition, vol. 27, no. 9, pp. 916-925, 1974.

[4] R. B. Mazess and W. E. Mather, "Bone mineral content in Canadian Eskimos," Human Biology, vol. 47, no. 1, pp. 45-63, 1975.

[5] I. G. Pawson, "Radiographic determination of excessive bone loss in Alaskan Eskimos," Human Biology, vol. 46, no. 3, pp. 369380, 1974.

[6] D. D. Thompson and M. Gunness-Hey, "Bone mineral-osteon analysis of Yupik-Inuping skeletons," American Journal of Physical Anthropology, vol. 55, no. 1, pp. 1-7, 1981.

[7] D. D. Thompson, "Age changes in bone mineralization, cortical thickness, and haversian canal area," Calcified Tissue International, vol. 31, no. 1, pp. 5-11, 1980.

[8] D. D. Thompson, E. M. Salter, and W. S. Laughlin, "Bone core analysis of Baffin Island skeletons," Arctic Anthropology, vol. 18, no. 1, pp. 87-96, 1981.

[9] A. B. Harper, W. S. Laughlin, and R. B. Mazess, "Bone mineral content in St. Lawrence Island Eskimos," Human Biology, vol. 56, no. 1, pp. 63-78, 1984.

[10] M. F. Ericksen, "Patterns of microscopic bone remodeling in three aboriginal American populations," in Early Native Americans: Prehistoric Demography, Economy, and Technology, D. L. Browman, Ed., pp. 239-270, Mouton Publishers, The Hague, The Netherlands, 1980.

[11] E. A. Richman, D. J. Ortner, and F. P. Schulter-Ellis, "Differences in intracortical bone remodeling in three aboriginal American populations: possible dietary factors," Calcified Tissue International, vol. 28, no. 3, pp. 209-214, 1979.

[12] S. Côté, P. Ayotte, S. Dodin et al., "Plasma organochlorine concentrations and bone ultrasound measurements: a cross-sectional study in peri-and postmenopausal Inuit women from Greenland," Environmental Health, vol. 5, article 33, 2006. 
[13] R. B. Martin, D. B. Burr, and M. B. Schaffler, "Effects of age and sex on the amount and distribution of mineral in Eskimo tibiae," American Journal of Physical Anthropology, vol. 67, no. 4, pp. 371-380, 1985.

[14] J. J. Filner, K. D. Krohn, J. A. Lapidus, and T. M. Becker, "Risk factors for osteoporosis in Alaska Native women: a crosssectional survey," Alaska Medicine, vol. 44, no. 1, pp. 8-21, 2002.

[15] L. Rejnmark, M. E. Jorgensen, M. B. Pedersen et al., "Vitamin $\mathrm{D}$ insufficiency in greenlanders on a westernized fare: ethnic differences in calcitropic hormones between greenlanders and danes," Calcified Tissue International, vol. 74, no. 3, pp. 255-263, 2004.

[16] A. C. Paunescu, P. Ayotte, E. Dewailly et al., "Polyunsaturated fatty acids and calcaneal ultrasound parameters among Inuit women from Nuuk (Greenland): a longitudinal study,' International Journal of Circumpolar Health, vol. 72, Article ID 20988, 2013.

[17] P. Laugier, "Quantitative ultrasound instrumentation for bone in vivo characterization," in Bone Quantitative Ultrasound, Springer Science+Business Media B.V, P. Laugier and G. Haïat, Eds., Chapter 3, pp. 47-71, 2011.

[18] M. A. Krieg, R. Barkmann, S. Gonnelli et al., "Quantitative ultrasound in the management of osteoporosis: the 2007 ISCD Official Positions," Journal of Clinical Densitometry, vol. 11, no. 1, pp. 163-187, 2008.

[19] F. Padilla and P. Laugier, "Recent developments in trabecular bone characterization using ultrasound," Current Osteoporosis Reports, vol. 3, no. 2, pp. 64-69, 2005.

[20] J. Dequeker, J. Ranstam, J. Valsson, B. Sigurgevisson, and E. Allander, "The Mediterranean Osteoporosis (MEDOS) Study questionnaire," Clinical Rheumatology, vol. 10, no. 1, pp. 54-72, 1991.

[21] G. Godin and R. J. Shephard, "A simple method to assess exercise behavior in the community," Canadian Journal of Applied Sport Sciences, vol. 10, no. 3, pp. 141-146, 1985.

[22] J. L. Newton, D. E. J. Jones, K. Wilton, J. Pairman, S. W. Parry, and R. M. Francis, "Calcaneal bone mineral density in older patients who have fallen," QJM-Monthly Journal of the Association of Physicians, vol. 99, no. 4, pp. 231-236, 2006.

[23] Santé Canada, "Lignes directrices canadiennes pour la classification du poids chez les adultes," 2013, http://www.hcsc.gc.ca/fn-an/nutrition/weights-poids/guide-ld-adult/indexfra.php.

[24] V. T. T. Hien, N. C. Khan, N. T. Lam et al., "Determining the prevalence of osteoporosis and related factors using quantitative ultrasound in Vietnamese adult women," American Journal of Epidemiology, vol. 161, no. 9, pp. 824-830, 2005.

[25] H. F. Saadi, R. L. Reed, A. O. Carter, E. V. Dunn, H. S. Qazaq, and A. R. Al-Suhaili, "Quantitative ultrasound of the calcaneus in Arabian women: relation to anthropometric and lifestyle factors," Maturitas, vol. 44, no. 3, pp. 215-223, 2003.

[26] C. Blanchet, Y. Giguère, D. Prud'homme et al., "Leisure physical activity is associated with quantitative ultrasound measurements independently of bone mineral density in postmenopausal women," Calcified Tissue International, vol. 73, no. 4, pp. 339-349, 2003.

[27] S. Adami, S. Giannini, R. Giorgino et al., "The effect of age, weight, and lifestyle factors on calcaneal quantitative ultrasound: the ESOPO study," Osteoporosis International, vol. 14, no. 3, pp. 198-207, 2003.

[28] C. Heldan de Moura Castro, M. Medeiros Pinheiro, and V. Lúcia Szejnfeld, "Quantitative ultrasound of the calcaneus in
Brazilian Caucasian women: normative data are similar to the manufacturer's normal range," Osteoporosis International, vol. 11, no. 11, pp. 923-928, 2000.

[29] W. Liu, C. L. Xu, Z. Q. Zhu, S. M. Han, S. Y. Zu, and G. J. Zhu, "Assessment of low quantitative ultrasound values of calcaneus in chinese mainland women," Journal of Clinical Densitometry, vol. 9, no. 3, pp. 351-357, 2006.

[30] J. Yamaguchi, G. Truman, and I. D. Cameron, "Lifestyle factors affecting bone ultrasonometry of the calcaneus in Japanese women," Calcified Tissue International, vol. 66, no. 1, pp. 43-46, 2000.

[31] J.-D. Lin, J.-F. Chen, H.-Y. Chang, and C. Ho, "Evaluation of bone mineral density by quantitative ultrasound of bone in 16 862 subjects during routine health examination," British Journal of Radiology, vol. 74, no. 883, pp. 602-606, 2001.

[32] B. Durmaz, S. Öncel, Y. Kirazli et al., "Quantitative calcaneal ultrasonometry: normative data and age-related changes for stiffness index in the Turkish population," Journal of Clinical Densitometry, vol. 9, no. 2, pp. 217-221, 2006.

[33] S. Maggi, M. Noale, S. Gonnelli et al., "Quantitative ultrasound calcaneous measurements: normative data for the Italian population. The ESOPO Study," Journal of Clinical Densitometry, vol. 10, no. 3, pp. 340-346, 2007.

[34] E. Babaroutsi, F. Magkos, Y. Manios, and L. S. Sidossis, "Lifestyle factors affecting heel ultrasound in Greek females across different life stages," Osteoporosis International, vol. 16, no. 5, pp. 552561, 2005.

[35] S. Migliaccio, E. A. Greco, R. Fornari, L. M. Donini, and A. Lenzi, "Is obesity in women protective against osteoporosis?" Diabetes, Metabolic Syndrome and Obesity, vol. 4, pp. 273-282, 2011.

[36] T. K. Young, "Are the circumpolar inuit becoming obese?" American Journal of Human Biology, vol. 19, no. 2, pp. 181-189, 2007.

[37] T. K. Young, P. Bjerregaard, E. Dewailly, P. M. Risica, M. E. Jørgensen, and S. E. O. Ebbesson, "Prevalence of obesity and its metabolic correlates among the circumpolar inuit in 3 countries," American Journal of Public Health, vol. 97, no. 4, pp. 691-695, 2007.

[38] C. M. Bernaards, J. W. R. Twisk, J. Snel, W. Van Mechelen, P. Lips, and H. C. G. Kemper, "Smoking and quantitative ultrasound parameters in the calcaneus in 36-year-old men and women," Osteoporosis International, vol. 15, no. 9, pp. 735-741, 2004.

[39] A. Welch, J. Camus, N. Dalzell, S. Oakes, J. Reeve, and K. T. Khaw, "Broadband ultrasound attenuation (BUA) of the heel bone and its correlates in men and women in the EPIC-Norfolk cohort: a cross-sectional population-based study," Osteoporosis International, vol. 15, no. 3, pp. 217-225, 2004.

[40] P. Hadji, O. Hars, M. Schüler et al., "Assessment by quantitative ultrasonometry of the effects of hormone replacement therapy on bone mass," American Journal of Obstetrics \& Gynecology, vol. 182, no. 3, pp. 529-534, 2000.

[41] P. Salari, A. Rezaie, B. Larijani, and M. Abdollahi, "A systematic review of the impact of n-3 fatty acids in bone health and osteoporosis," Medical Science Monitor, vol. 14, no. 3, pp. RA37RA44, 2008.

[42] P. Albertazzi and K. Coupland, "Polyunsaturated fatty acids. Is there a role in postmenopausal osteoporosis prevention," Maturitas, vol. 42, no. 1, pp. 13-22, 2002. 
[43] M. Maggio, A. Artoni, F. Lauretani et al., "The impact of omega3 fatty acids on osteoporosis," Current Pharmaceutical Design, vol. 15, no. 36, pp. 4157-4164, 2009.

[44] N. Malavolta, R. Mule, and M. Frigato, "Quantitative ultrasound assessment of bone," Aging Clinical and Experimental Research, vol. 16, no. 3, pp. 23-28, 2004.

[45] A. Moayyeri, J. E. Adams, R. A. Adler et al., "Quantitative ultrasound of the heel and fracture risk assessment: an updated meta-analysis," Osteoporosis International, vol. 23, no. 1, pp. 143153, 2012.

[46] R. D. Danese and A. A. Licata, "Ultrasound of the skeleton: review of its clinical applications and pitfalls," Current Rheumatology Reports, vol. 3, no. 3, pp. 245-248, 2001.

[47] C. M. Langton and C. F. Njeh, "The measurement of broadband ultrasonic attenuation in cancellous bone-a review of the science and technology," IEEE Transactions on Ultrasonics, Ferroelectrics, and Frequency Control, vol. 55, no. 7, pp. 1546-1554, 2008.

[48] M. F. Holick, "Sunlight and vitamin D for bone health and prevention of autoimmune diseases, cancers, and cardiovascular disease," The American Journal of Clinical Nutrition, vol. 80, no. 6, pp. 1678-1688, 2004. 


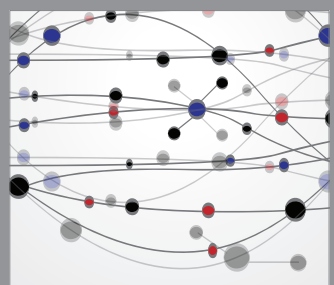

The Scientific World Journal
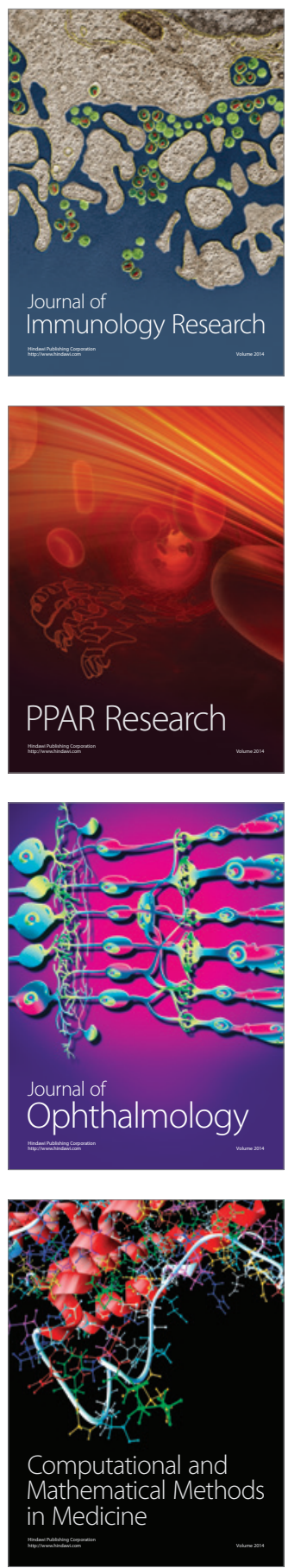

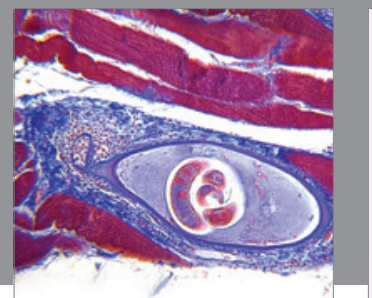

Gastroenterology

Research and Practice
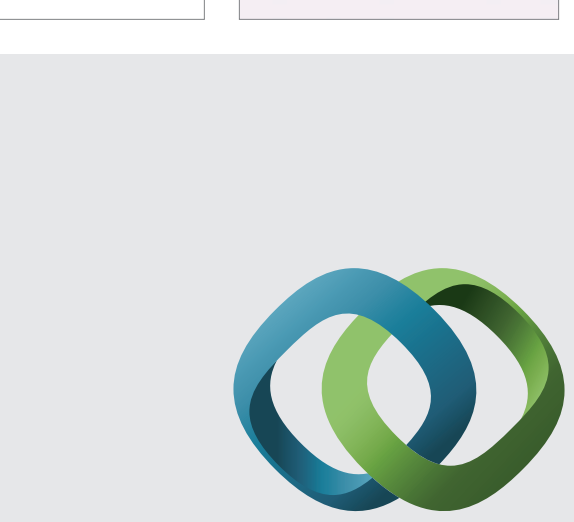

\section{Hindawi}

Submit your manuscripts at

http://www.hindawi.com
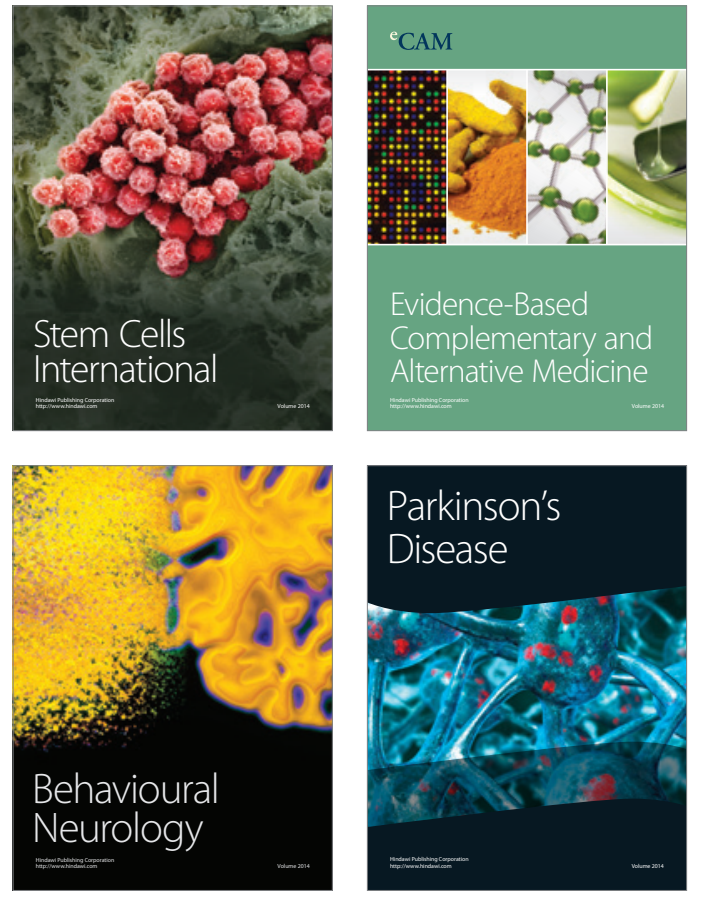
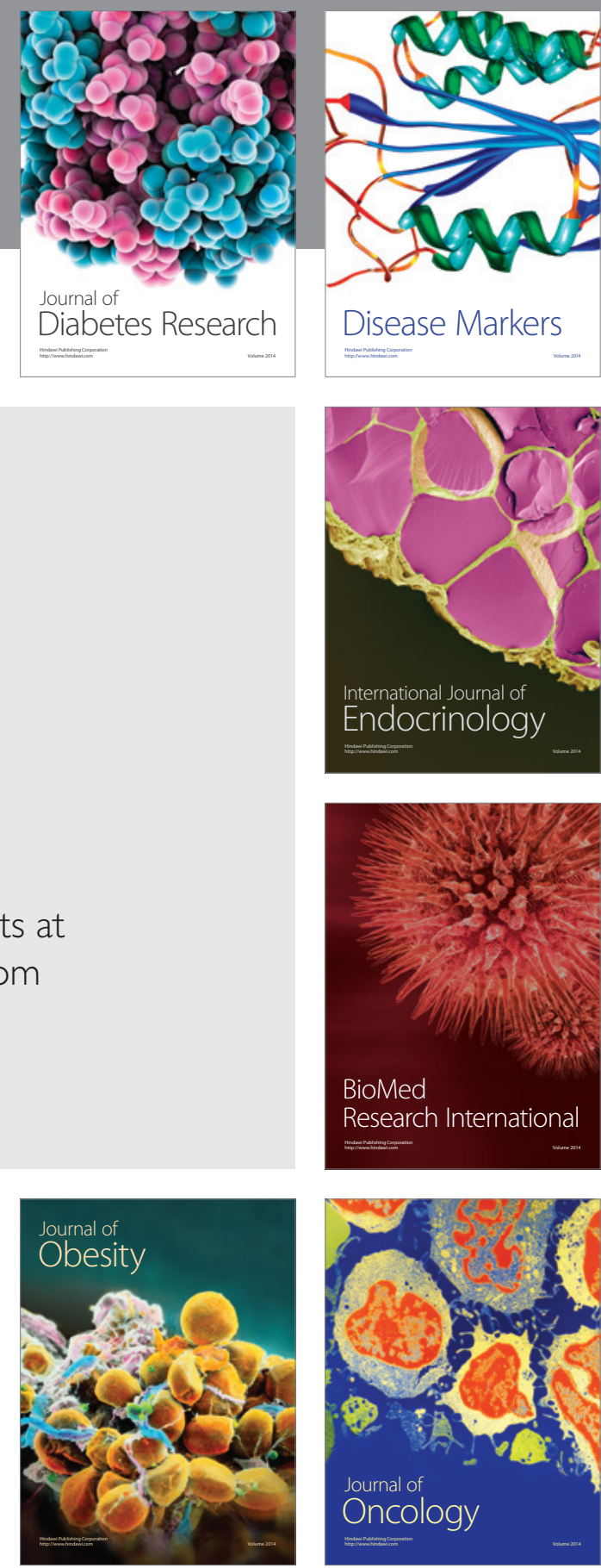

Disease Markers
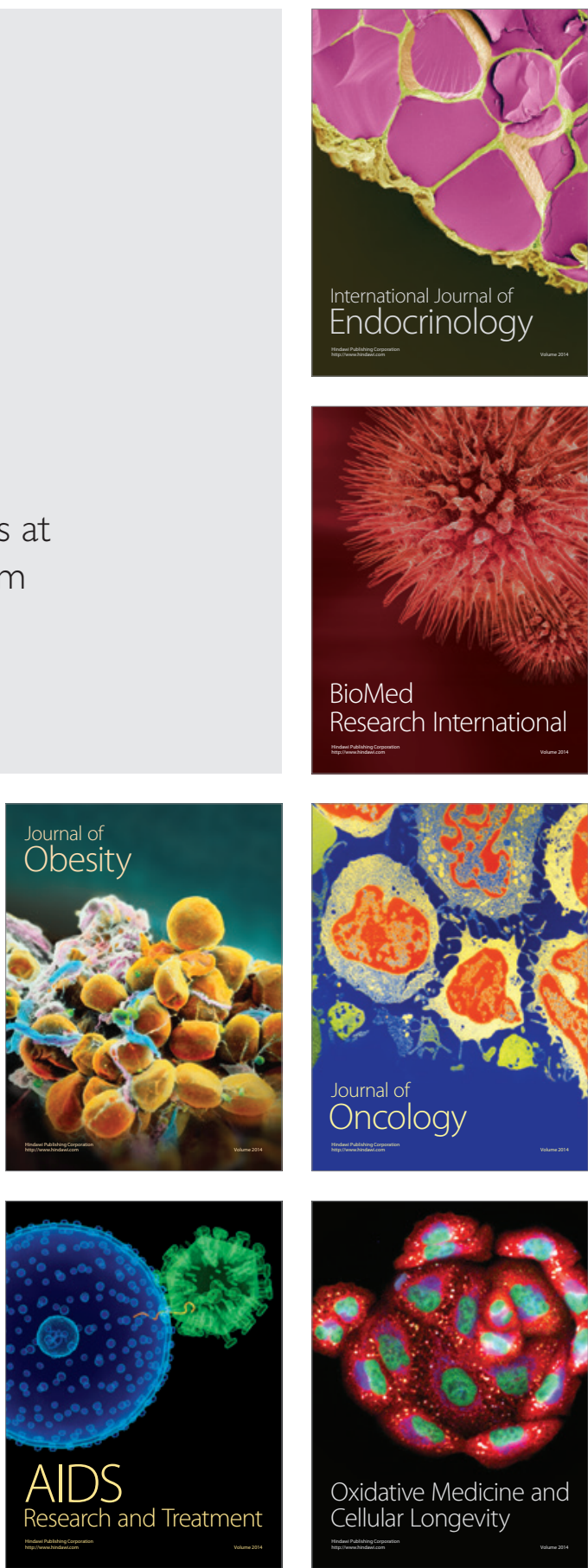